\title{
Adolescent alcohol and cannabis use in Iceland 1995-2015
}

\author{
ARSAELL ARNARSSON ${ }^{1,2}$ (D), GISLI KORT KRISTOFERSSON ${ }^{3} \&$ THORODDUR BJARNASON $^{1}$ \\ ${ }^{1}$ School of Humanities and Social Sciences, University of Akureyri, Akureyri, Iceland, ${ }^{2}$ School of Education, University of \\ Iceland, Reykjavik, Iceland, and ${ }^{3}$ School of Health Sciences, University of Akureyri, Akureyri, Iceland
}

\begin{abstract}
Introduction. Over the past two decades, alcohol consumption of Icelandic adolescents has decreased dramatically. The aim of this study was to quantify the extent of this reduction and compare it with the trend in cannabis use over a 20 year period and to identify possible explanations. Methods. We used data from the Icelandic participants to the European School Survey Project on Alcohol and Other Drugs study (collected via paper-and-pencil questionnaires in classrooms). The sample included all students in the 10th grade (54-89\% response rate). Results. The percentage of participants who had never used alcohol during their lifetime rose from $20.8 \%$ in 1995 to $65.5 \%$ in 2015. Similarly, there was a decline in the proportion of students who had consumed alcohol 40 times or more, from $13.7 \%$ to $2.8 \%$. During the same period, the number of students who had never used cannabis rose from 90.2\% to 92.0\%. In contrast, we found a small, but statistically significant, increase in the prevalence of those who had used cannabis 40 times or more, from $0.7 \%$ in 1995 to 2.3\% in 2015. Parental monitoring increased markedly between 1995 and 2015, but availability of alcohol decreased. Perceived access to cannabis and youth attitudes towards substance use remained unchanged. Discussion. Although Iceland has enjoyed success in lowering alcohol use among adolescents over the past decades, and somewhat fewer claim to have ever tried cannabis, there has been a threefold increase among heavy users of cannabis. Increased parental monitoring and decreased availability of alcohol explain some of the changes seen. [Arnarsson A, Kristofersson GK, Bjarnason T. Adolescent alcohol and cannabis use in Iceland 1995-2015. Drug Alcohol Rev 2018;37:S49-S57]
\end{abstract}

Key words: adolescence, cannabis, alcohol, parental monitoring, perceived risk.

\section{Introduction}

Adolescence is a transition between childhood and adulthood and marked by experimentation in a variety of ways. It is a normal part of this process that the individual seeks more independence from their parents and spends more unsupervised time with friends. Most of the experimentation involves trying out more adultlike behaviour and in some instances breaking norms. Adolescence is obviously a very important period with regard to the use of legal and illegal substances, as individuals experiment with behaviour and form habits that will often follow them into to adulthood-for better or worse. Their vulnerable developing brain can also be affected more severely by abuse than the adult one. Individuals who start using substances at an early age are more likely to become poly-substance users, suffer from addiction, and health and psychological problems later in life [1-3]. It is therefore no wonder that authorities all over the world place great value on effective prevention policies targeting this age group.
Over the past two decades, there has been a marked decrease in alcohol consumption of Icelandic adolescents, which has among other things been linked to government-sponsored primary prevention programs. This has been established both in local studies as well as with Iceland's participation in the European School Survey Project on Alcohol and Other Drugs (ESPAD) [4-6]. During this time period, alcohol consumption of European adolescents has been more or less unchanged. Other Nordic countries have also enjoyed a noticeable reduction in adolescent alcohol use, but to a lesser degree. The relative position of Icelandic adolescents with regard to the prevalence of adolescent alcohol use has thus changed from being close to the European average in 1995 to being the lowest in Europe in $2016[6,7]$.

However, as youth researchers with close connections with people working in the field, we are inundated with reports of problematic substance abuse among adolescents that do not fit with the general trend in Iceland. There are two possible explanations

Arsaell Arnarsson PhD., Gisli Kort Kristofersson PhD, Thoroddur Bjarnason Ph.D. Correspondence to Dr Arsaell Arnarsson, School of Humanities and Social Sciences, University of Akureyri, IS-600 Akureyri, Iceland. Tel: +354 4608000; Fax: +354 4608999; E-mail: aarnarsson@unak.is 
for this discrepancy: firstly, that people working in the problem or secondly, that our analysis of data has been too superficial and has not taken into account development in heavy drinking or a shift towards cannabis. The latter is of particular importance because from 1995 to 2011, there was an overall increase in cannabis use seen in the ESPAD study across Europe [6]. Data from three cycles (2002, 2006 and 2010) of the Health Behaviour in School-aged Children (HBSC) study among 30 European and North American countries found that cannabis use had declined in more affluent countries, but was stable or on the rise in emerging market countries. It also showed cannabis use to be more common among adolescent boys than girls [8], which is in accordance with the results from the ESPAD study [6].

It is also of utmost importance to identify the factors associated with this established increase in alcohol abstinence among Icelandic adolescents, both to see how they affect use of other substances, such as cannabis, and also to be able to describe best practices for others to adapt. Are these factors related to the adolescents themselves, their parents, the wider society or some combination of the three? The theoretical framework of problem behaviour theory proposes that risk behaviours, such as drug and alcohol use, general delinquency and early sexual initiation cluster together as part of a negative developmental pattern of behaviours [9]. According to this theory, the decline in adolescent drinking should be accompanied with a reduction in other harmful behaviour patterns, such as cannabis use.

The aim of this study was threefold: (i) to examine trends of alcohol drinking and cannabis use in Iceland to provide more detailed information for health workers in the field; (ii) to examine whether decrease alcohol drinking has been replaced by increased cannabis use; and (iii) to examine in what way perceived risk of use, parental monitoring and availability of substances influence use of cannabis and alcohol. These three factors can be seen as measurements of individual, parental and societal influences. On an individual level, studies have shown that having favourable attitudes or expectancies towards alcohol or cannabis use can exacerbate risk of problematic use [10]. The effects of parental monitoring during late childhood and early adolescence are especially relevant because a part of normal development involves the adolescent breaking free from the parents and establishing independence and taking risks. Parents are thereby put in the ambivalent position of having to relinquish power, but at the same time, to protect the child from harmful behaviour, such as substance use [11]. On a more societal level, the availability of substances has also been shown to increase use [8]. The effects of all three factors are tested in our study.

\section{Methods}

We used data from the Icelandic participants to the ESPAD study, which Iceland has been a part of since the first wave in 1995. Data have since been gathered every fourth year until 2015 in the months of January to March.

Before each wave, a similar procedure was followed. First, the Icelandic Data Protection Authority approved the study protocol. Then the principals in all Icelandic schools were contacted and introduced to the planned study. They were asked to inform the teachers of the 10th grade class(es), but not to inform the students in order to avoid discussions among them, which could lead to biased data. The class teachers were asked to schedule the survey for one lecture following the same procedure as for a written test. Data were collected under the supervision of a teacher or a research assistant. The study employed a standard school survey methodology with questionnaires administered anonymously with a blank envelope procedure to all students present in class on the day of the surveys. Student desks were moved apart to ensure privacy, and each student put his or her questionnaire in a sealed envelope upon completion. At the end of the survey, all envelopes were collected in boxes and sealed for transportation. Students were therefore fully aware that their responses were anonymous and could never be traced back to them [6].

The sample has included all Icelandic students in the compulsory 10th grade of secondary school, of which 3.814 responded in 1995 and 2.336 in 2015 (Table 1). Only students in special schools for severely disabled students were not included. The drop in participation rates in 2015 was due to sudden and unforeseen problems with staffing during the period of field work. This meant that we were unable to enrol the usual number of schools. Fewer schools participated, but they were chosen randomly.

To assess alcohol consumption, the participants were asked on how many occasions (if any) they had had any alcoholic beverage to drink during their

Table 1. Participating students and response rates

\begin{tabular}{|c|c|c|c|c|c|c|}
\hline & \multicolumn{3}{|c|}{$\begin{array}{l}\text { Number of participating } \\
\text { students }\end{array}$} & \multicolumn{3}{|c|}{ Response rate (\%) } \\
\hline & Boys & Girls & Total & Boys & Girls & Total \\
\hline 1995 & 1931 & 1878 & 3814 & 86 & 88 & 87 \\
\hline 1999 & 1758 & 1766 & 3524 & 89 & 89 & 89 \\
\hline 2003 & 1728 & 1604 & 3348 & 82 & 80 & 81 \\
\hline 2007 & 1797 & 1713 & 3510 & 80 & 81 & 81 \\
\hline 2011 & 1717 & 1616 & 3333 & 80 & 81 & 81 \\
\hline 2015 & 1144 & 1180 & 2336 & 53 & 54 & 54 \\
\hline
\end{tabular}


lifetime. They were also asked on how many occasions (if any) they had used cannabis (marijuana or hashish). The possible answers for both questions ranged from ' 0 ' to ' 40 or more'. The participants were also asked to estimate how difficult it would be for them to get beer, spirits or cannabis if they wanted. They could answer 'Impossible', 'Very difficult', 'Fairly difficult', 'Fairly easy', 'Very easy' or 'Don't know'. Finally, the participants were asked 'How much do you think people risk harming themselves (physically or in other ways), if they: (i) have five or more drinks each weekend; or (ii) smoke marijuana or hashish (cannabis) regularly'. The answers were 'No risk', 'Slight risk', 'Moderate risk', 'Great risk' or 'Don't know'.

Prevalence was calculated with 95\% confidence intervals (CI), and significance of change was examined using Pearson's $\chi^{2}$-test. Logistic regression with odds ratio (OR) was used to explain relations between dependent and independent variables.

\section{Results}

The percentage of participants who had never used alcohol during their lifetime rose from $20.8 \%$ in 1995 to $65.5 \%$ in 2015 . During the same period, the number of students who had never used cannabis rose from $90.2 \%$ to $92.0 \%$ (Figure 1 ).

As Figure 2 shows, there was also a decline in the proportion of students who had consumed alcohol 40 times or more often, from $13.7 \%$ in 1995 to $2.8 \%$ in 2015. There was however a marked increase in the prevalence of those who had used cannabis 40 times or more in the same period, from $0.7 \%$ to $2.3 \%$.

No major difference was found between the sexes in abstaining or frequent use of alcohol or cannabis in the 20 year period. As Table 2 demonstrates, girls were similar to boys on all of these measures in the beginning of the study period as they were in the end. It was only in 1995 that girls were less likely to be frequent

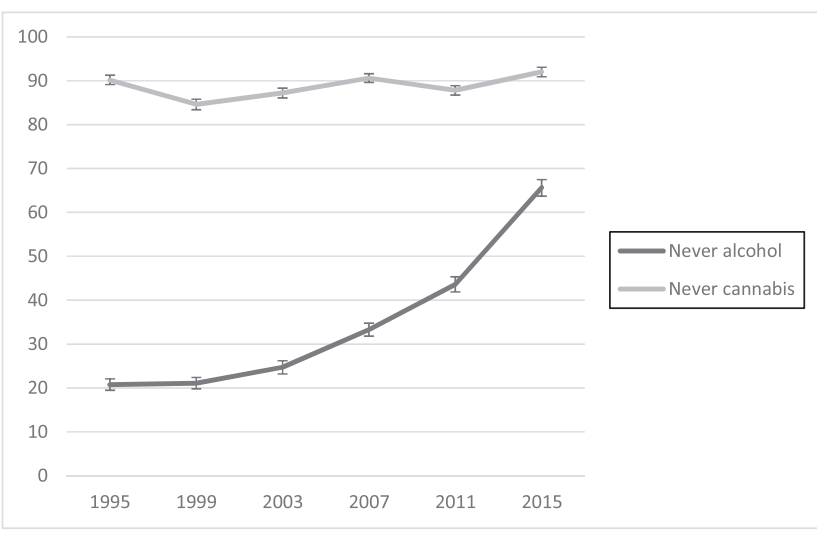

Figure 1. Percentage of Icelandic 10th graders who had never used alcohol or cannabis (95\% confidence interval).

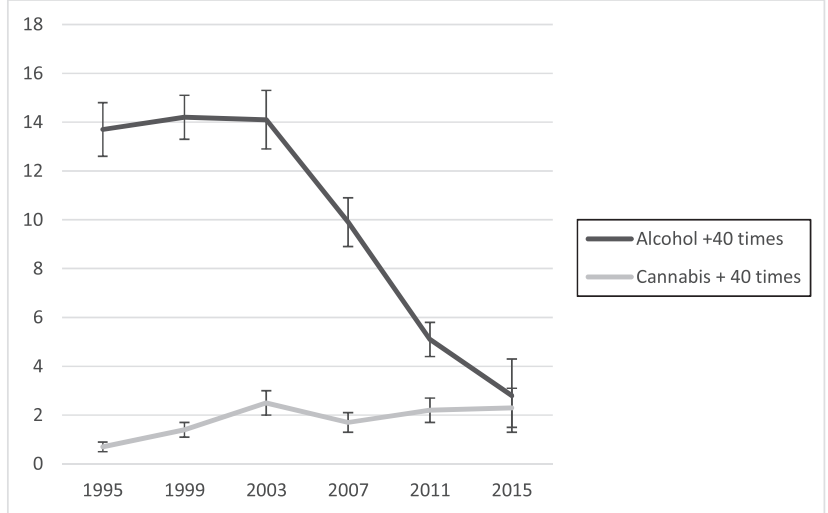

Figure 2. Percentage of Icelandic 10th graders who had used alcohol or cannabis on 40 or more occasions ( $95 \%$ confidence interval).

users of cannabis $(P<0.01)$. The reduction in alcohol use from 1995 to 2015 was not replaced with a general increase in cannabis use during the same period.

As Table 2 shows, we found substantial overlap between the groups that had most often drunk alcohol and those that had most frequently used cannabis both at the beginning of the survey in 1995 and in the most recent one in 2015. Out of 27 adolescents who claimed to have used cannabis 40 times or more in 1995, 21 $(77.8 \%)$ were also heavy alcohol users. Only one heavy user of cannabis had never used alcohol. Among the 509 heavy users of alcohol in 1995, 21 (4.1\%) had also used cannabis 40 times or more in their lifetime, and a further $39.5 \%$ reported some cannabis use. In our dataset from 2015 , a total of $40.6 \%(N=26)$ of those who had used alcohol 40 times or more in their lifetime had also used cannabis as frequently. This means that among heavy users of alcohol, 10 times more were also heavy users of cannabis in 2015 than were so in 1995. Only $26.6 \%$ (17) of the adolescents who had drunk alcohol so often had never used cannabis. One individual among the highest cannabis users in 2015 had never drank alcohol, and half of them were also heavy users of alcohol.

Importantly, Table 2 also shows that the decrease in alcohol drinking has not entailed an increase in cannabis use. The proportion of non-drinkers who use cannabis is unchanged from 1995 to 2015. In $1995,99.4 \%$ (773/778) of non-drinkers had not used cannabis whereas the corresponding number in 2015 was $99.3 \%(1499 / 1510)$.

Table 3 shows changes in students' perception from 1995 to 2015 of how difficult it would be for them to get beer, spirits or cannabis (marijuana or hashish) if they wanted. The availability of beer has decreased significantly over this period with sharp drops seen both between 2003 and 2007 and again from 2007 to 2011 $(P<0.01)$. The reduction in the accessibility of spirits has been steady after $2003(P<0.01)$. Furthermore, 
Table 2. Use of alcohol and cannabis by Icelandic 10th graders in 1995 compared with 2015 in percentages (N) and divided by sex

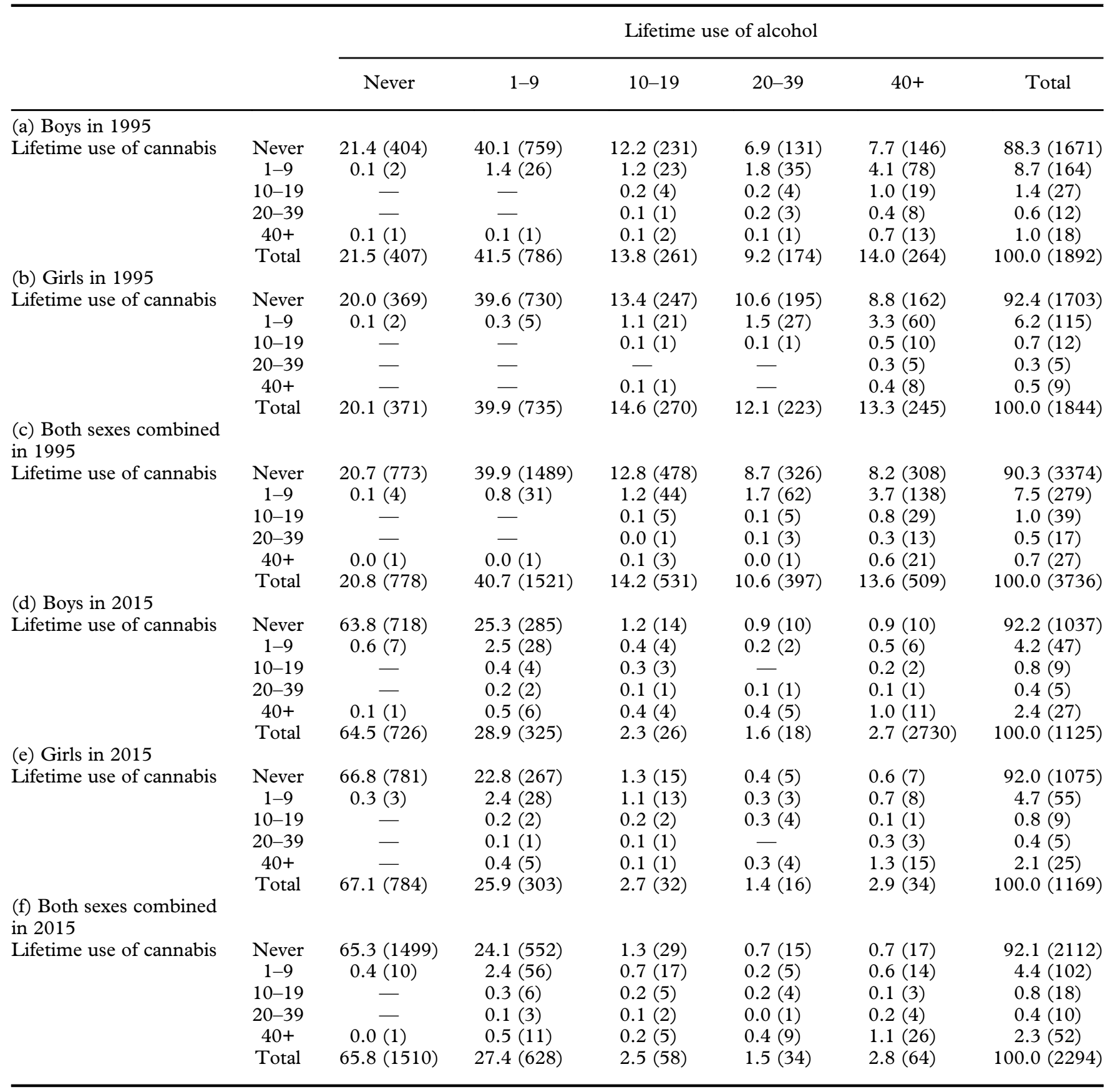

significantly more adolescents seem unsure about easily obtainable alcohol is for them $(P<0.01)$. Table 3 shows a greater reduction in the availability of spirits relative to beer. This might reflect the overall trend in total alcohol consumption in Iceland during this period, where sales of spirits has declined while sales of beer has remained more stable. The perceived availability of cannabis has however remained remarkably stable during this 20 year period, apart from a slight increase in 1999 and 2003.
Table 4 shows changes over a 20 year period in attitudes towards the harm involved in regular use of either alcohol or cannabis. Participants were asked how much people risked harming themselves (physically or in other ways) if they either had five or more drinks every weekend or smoked cannabis regularly. There was a slight polarisation in the estimation of risk due to regular consumption of alcohol-a higher percentage of adolescents had stronger views about the risk posed in 2015 than their peers in 1995 had 
Table 3. Changes in perceived availability of (a) beer, (b) spirits and (c) cannabis from 1995 to 2015

\begin{tabular}{|c|c|c|c|c|c|c|}
\hline & 1995 & 1999 & 2003 & 2007 & 2011 & 2015 \\
\hline \multicolumn{7}{|c|}{ (a) Changes in perceived availability of beer-percentage (95\% CI) } \\
\hline Impossible & $1.3(0.9-1.6)$ & $1.1(0.7-1.4)$ & $1.9(1.2-2.5)$ & $5.0(4.3-5.7)$ & $12.4(11.3-13.5)$ & $11.9(10.6-13.3)$ \\
\hline Fairly difficult & $6.2(5.4-6.9)$ & $5.1(4.3-5.8)$ & $5.8(4.6-6.9)$ & $8.3(7.4-9.2)$ & $11.6(10.5-12.6)$ & $11.9(10.6$ \\
\hline Fairly easy & $28.0(26.4-29.2)$ & $31.7(30.1-33.2)$ & $35.6(33.3-37.9)$ & $32.4(30.9-33.9)$ & $22.7(21.3-24.1)$ & $31.1(29.2-32.9)$ \\
\hline Very easy & $59.3(57.7-60.9)$ & $58.9(57.3-60.5)$ & $51.9(49.5-54.4)$ & $38.1(35.5-39.7)$ & $21.7(20.4-23.1)$ & $22.2(20.5-23.9)$ \\
\hline Impossible & $4.5(3.8-5.2)$ & $2.6(2.1-3.1)$ & $4.2(3.2-5.2)$ & $10.3(9.3-11.3)$ & $14.6(13.4)$ & $21.1(19.4-22.7)$ \\
\hline Very difficult & $5.5(4.8-6.2)$ & $4.5(3.8-5.2)$ & $5.7(4.5-6$ & $8.6(7$. & $9.7(8$ & 15.6( \\
\hline Fairly difficult & $10.5(9.6-11.5)$ & $10.1(9.1-11.1)$ & $12.2(10.6-13.7)$ & $11.5(10.4-12.5)$ & $10.9(9.8-11.9)$ & $13.4(12.0-14.8)$ \\
\hline Fairly easy & $25.5(24.1-26.9)$ & $30.2(28.7-31.7)$ & $27.0(24.8-29.1)$ & $25.3(23.9-26.7)$ & $21.1(19.7-22.5)$ & $17.8(16.3-19.4)$ \\
\hline Very easy & $48.8(47.2-50.4)$ & $47.9(46.2-49.5)$ & $44.2(41.8-46.6)$ & $29.6(28.1-31.1)$ & $24.1(22.7-25.6)$ & $16.4(14.9-17.9)$ \\
\hline Don't know & $5.1(4.4-5.8)$ & $4.7(4.0-5.4)$ & $6.8(5.6-8.0)$ & $14.7(13.6-15.9)$ & $19.5(18.2-20.8)$ & $15.7(14.2-17.2)$ \\
\hline \multicolumn{7}{|c|}{ (c) Changes in perceived availability of cannabis - percentage $(95 \% \mathrm{CI})$} \\
\hline Fairly easy & $16.7(15.5-17.9)$ & $24.7(23.3-26.1)$ & $21.9(20.0-23.9)$ & $15.3(14.1-16.5)$ & $14.8(13.6-15.9)$ & $17.1(15.6-18.7)$ \\
\hline Very easy & $10.6(9.6-11.6)$ & $12.9(11.8-14.0)$ & $14.3(12.6-15.9)$ & $8.8(7.9-9.7)$ & $11.7(10.6-12.8)$ & $11.0(9.8-12.3)$ \\
\hline Don't know & $18.7(17.4-19.9)$ & $19.0(17.7-20.3)$ & $19.8(17.9-21.8)$ & $21.5(20.1-22.8)$ & $23.4(22.0-24.9)$ & $17.4(15.9-19.0)$ \\
\hline
\end{tabular}

CI, confidence interval.

Table 4. Perceived risk of regular use of (a) alcohol and (b) cannabis

\begin{tabular}{|c|c|c|c|c|c|c|}
\hline \multicolumn{7}{|c|}{ (a) Risk of drinking five or more drinks each weekend-percentage (95\% CI) } \\
\hline No risk & $2.3(1.9-2.8)$ & $2.3(1.8-2.8)$ & $5.2(4.1-6.3)$ & $4.0(3.4-4.7)$ & $3.6(3.0-4.2)$ & $5.0(4.1-5.8)$ \\
\hline Slight risk & $14.1(13.0-15.2)$ & $17.5(16.3-18.8)$ & $19.9(18.0-21.9)$ & $16.6(15.4-17.8)$ & $7.9(7.0-8.8)$ & $9.3(8.1-10.5)$ \\
\hline Moderate risk & $43.1(41.6-44.7)$ & $42.9(41.2-44.5)$ & $39.1(36.8-41.5)$ & $35.7(34.2-37.3)$ & $30.6(29.0-32.1)$ & $32.0(30.2-34.0)$ \\
\hline Great risk & $36.6(35.1-38.1)$ & $34.0(32.4-35.6)$ & $31.7(29.5-34.0)$ & $38.2(36.7-39.8)$ & $49.9(48.3-51.6)$ & $46.6(44.5-48.6)$ \\
\hline Don't know & $3.8(3.2-4.4)$ & $3.3(2.7-3.9)$ & $4.0(3.1-5.0)$ & $5.4(4.6-6.1)$ & $8.0(7.1-8.9)$ & $7.1(6.0-8.1)$ \\
\hline No risk & $1.1(0.7-1.4)$ & $1.0(0.7-1.4)$ & $2.1(1.4-2.8)$ & $2.8(2.3-3.3)$ & $4.5(3.8-5.2)$ & $6.1(5.1-7.1)$ \\
\hline Slight risk & $0.8(0.5-1.1)$ & $1.4(1.0-1.8)$ & $2.2(1.5-2.9)$ & $1.6(1.2-2.0)$ & $4.3(3.6-5.0)$ & $4.6(3.7-5.4)$ \\
\hline Moderate risk & $5.5(4.8-6.3)$ & $7.5(6.7-8.4)$ & $8.6(7.3-10.0)$ & $7.7(6.9-8.6)$ & $11.1(10.1-12.2)$ & $11.7(10.4-13.1)$ \\
\hline Great risk & $89.1(88.1-90.1)$ & $87.1(85.9-88.2)$ & $83.0(81.2-84.8)$ & $83.3(82.0-84.5)$ & $72.2(70.7-73.7)$ & $69.8(68.0-71.8)$ \\
\hline Don't know & $3.5(2.9-4.1)$ & $3.0(2.4-3.5)$ & $4.0(3.1-5.0)$ & $4.6(3.9-5.3)$ & $7.9(7.0-8.8)$ & $7.8(6.7-8.9)$ \\
\hline
\end{tabular}

CI, confidence interval. [Correction added on 02 March 2018, after first online publication: The values under section '(b) Risk of smoking marijuana or hashish (cannabis) regularly-percentage (95\% CI)' in Table 4 have been corrected.]

had. Significantly more students thought it entailed no risk $(P<0.01)$, but more also thought it posed great risk $(P<0.01)$. The percentage of those who were not sure also increased significantly from 1995 to $2015(P<0.01)$. The health risk of regular cannabis use was considered significantly less by students in 2015 than it had been in $1995(P<0.01)$. More students were also not sure about the risk $(P<0.01)$.

Two questions on parental monitoring were included in the 1995, 2007, 2011 and 2015 waves. They were framed from the point of view of the adolescents, that is, asking them to estimate their parents' knowledge of their whereabouts in the evenings as well as whom they are with. The percentage of parents knowing the whereabouts of their children in the evening has changed dramatically over the two decades. Ten times more adolescents in 1995 $(11.9 \%)$ than in $2015(1.7 \%)$ claimed that their parents almost never possess such information $(P<0.01)$. In $2015,67.3 \%$ said that their parents almost always know where they are compared with a $26.0 \%$ in $1995(P<0.01)$. Table 5 shows a more detailed analysis on the second question of parental monitoring - whether they know whom their children are with in the evening. In 1995, a quarter of all teenagers claimed that their parents almost never 
Table 5. Percentage of parents who know with whom their adolescent is in the evening in (a) 1995 and (b) 2015, divided by adolescent lifetime use of alcohol and cannabis

\begin{tabular}{|c|c|c|c|c|c|c|c|c|c|c|c|}
\hline & Total & Never & $1-9$ & $10-19$ & $20-39$ & Or more & Never & $1-9$ & $10-19$ & $20-39$ & Or more \\
\hline \multicolumn{12}{|l|}{ (a) In 1995 (\%) } \\
\hline Almost always & 14.7 & 16.8 & 15.9 & 12.6 & 13.7 & 11.1 & 15.2 & 10.2 & 0.0 & 16.7 & 14.8 \\
\hline Often & 17.6 & 17.7 & 17.4 & 18.5 & 21.9 & 15.0 & 17.7 & 17.3 & 12.8 & 22.2 & 11.1 \\
\hline $\begin{array}{l}\text { Almost never } \\
\text { (b) In } 2015 \text { (\%) }\end{array}$ & 25.2 & 25.2 & 23.5 & 23.8 & 24.9 & 30.8 & 25.1 & 27.6 & 25.6 & 22.2 & 25.9 \\
\hline Almost always & 66.9 & 76.2 & 53.1 & 48.2 & 35.3 & 19.7 & 69.6 & 40.4 & 27.8 & 30.0 & 28.6 \\
\hline Often & 20.2 & 15.8 & 29.1 & 19.6 & 26.5 & 26.2 & 19.6 & 26.3 & 27.8 & 50.0 & 22.4 \\
\hline Sometimes & 8.2 & 5.6 & 12.2 & 16.1 & 17.6 & 19.7 & 7.5 & 19.2 & 11.1 & 10.0 & 18.4 \\
\hline Seldom & 2.7 & 1.5 & 3.2 & 8.9 & 8.8 & 16.4 & 2.0 & 10.1 & 5.6 & 0.0 & 16.3 \\
\hline
\end{tabular}

CI, confidence interval.

knew who they were with at night, whereas the same applies to only $2 \%$ of students in $2015(P<0.01)$. Similarly, in 2015, two-thirds of adolescents thought that their parents almost always knew whom they were with in the evenings compared with around $15 \%$ in $1995(P<0.01)$. Also presented in Table 5 is the association between the percentage of parents who know whom their child is with in the evening with the adolescent experience of alcohol and cannabis. Looking at the numbers from 1995, there seems to be no clear cut relation between parental monitoring and adolescent substance use. In 2015, on the other hand, the two are negatively related.

We conducted binary logistic regression to predict risk of students' lifetime use of alcohol and cannabis using availability of these substances, parental monitoring, perceived risk of use and sex as predictors. The dependent variables were defined dichotomously as 'Never' versus 'Ever' users of alcohol or cannabis. The analysis was performed separately for the 1995 and 2015 datasets.

Looking at the risk of alcohol use in the 1995 cohort, we found that a test of the full model against the constant only model was statistically significant, indicating that the predictors as a set reliably distinguished between abstainers and drinkers $(P<0.001)$. For every category increase in the difficulty of obtaining alcohol, the risk of use is halved (OR 0.53; 95\% CI 0.48-0.58; $P<0.001)$. Each category increase in perceived risk of drinking decreased the risk of actually doing so by $66 \%$ (95\% CI $0.55-0.88 ; P<0.001)$. Parental monitoring was not found protective against drinking in 1995, but girls were less likely to be drinkers (OR 0.78; 95\% CI 0.65-0.94; $P<0.001$ ).

Our model predicted the risk of having ever tried cannabis in the 1995 cohort much better than it did the alcohol use $(P<0.001)$. For every category increase in the difficulty of obtaining cannabis, the risk of use is reduced by $68 \%$ (OR 0.32; 95\% CI $0.28-0.36 ; P<0.001)$. Each category decrease in perceived risk of cannabis use increased the risk of actually using 2.2-fold (95\% CI 1.75-2.79; $P<0.001)$. Parental monitoring was slightly protective against cannabis use in 1995 (OR 0.89; 95\% CI $0.81-0.98 ; P<0.05)$ as well as being female (OR 0.66 ; 95\% CI $0.24-0.97 ; P<0.05)$.

In analysing the 2015 wave, the full model was found to be statistically significant in predicting risk of having ever used alcohol $(P<0.001)$. For every category increase in the difficulty of obtaining alcohol, the risk of use is decreased by $42 \%$ (OR 0.58 ; 95\% CI 0.53-0.63; $P<0.001)$. Same decrease was found for each category increase in parental monitoring (OR 0.58; 95\% CI 0.51-0.65; $P<0.001$ ). Each category increase in perceived risk of drinking decreased the risk of actually doing so by $30 \%$ (OR $0.70 ; 95 \%$ CI $0.53-0.87 ; P<0.001)$. Sex was not found to predict drinking in 2015 .

Using the before mentioned variables to predict the risk of having ever used cannabis in the 2015, cohort revealed that for every category increase in the difficulty of obtaining cannabis, the risk of use is reduced by $72 \%$ (OR $0.28 ; 95 \%$ CI $0.22-0.35$; $P<0.001)$. Each category decrease in perceived risk of cannabis use increased the risk of actually using twofold (OR 2.04; 95\% CI 1.68-2.49; $P<0.001$ ). Increase in parental monitoring reduced the risk of cannabis use by $39 \%$ for each category (OR 0.61; 95\% 0.51-0.74; $P<0.001)$. Girls were also significantly less likely to be users (OR 0.55; 95\% CI 0.36-0.83; $P<0.01)$. 


\section{Discussion}

Although Iceland has enjoyed success in lowering alcohol use among adolescents over the past two decades, and somewhat fewer claim to have ever tried cannabis, there is a threefold increase in heavy users of cannabis during this period, and 10 times more heavy users of alcohol are now also heavy users of cannabis. This trend of heavy cannabis use among Icelandic students was also seen in the latest ESPAD report [12] where they rank at the top of the list of 35 European countries in frequency of use among students who had used cannabis. Icelandic boys who use cannabis had done so 14.5 times in the last 12 months and the girls 12.7 times. This does not however indicate that the reduction in alcohol use among Icelandic adolescents from 1995 to 2015 has been replaced by an increase in cannabis use. Rather, that while the majority of adolescents have reduced their substance use, a small minority show a contrary trend. The fact remains that it has been possible to reduce the most vulnerable group with regard to alcohol consumption in Iceland from $14.0 \%$ of boys and $13.4 \%$ of girls in 1995 to $2.6 \%$ of boys and $2.9 \%$ of girls in 2015 .

Availability of substances could be a crucial explanatory factor, as it has dramatically reduced in this 20 year period for alcohol, but remained remarkably unchanged to cannabis. This most likely reflects increasing reluctance of adults, especially parents, to purchase alcohol for their children. This decrease in adolescent alcohol consumption in Iceland is profoundly dissimilar to the development for the population as a whole, in which yearly consumption has risen from 4.7 litres of pure alcohol per capita in 1995 to 7.5 in 2014 [13]. The trend in cannabis consumption among Icelandic adolescents follows much more closely the pattern seen in the general population. In a 1997 survey of Icelanders 18-74 years old, $19 \%$ claimed to have used cannabis $1-$ 10 times, and $4 \%$ said that they had done so 10 or more times. A similar study in 2013 showed that the corresponding percentages were $23 \%$ and $8 \%$ [14]. The increase in cannabis consumption in all age groups in Iceland seems therefore to be among heavy users.

There are many possible factors at work, and it is important to take into account the development in other countries. The Nordic states are in many ways similar in terms of welfare and social policies. Six of them have participated in the ESPAD study from 1995. The decrease in alcohol consumption among teenagers has been similar in all these countries although the absolute numbers have varied greatly from the beginning. Changes in cannabis use across the Nordic countries have shown inconsistent trends from 1995. In the Faroe Islands, there has been a marked reduction and in Norway a slight decrease. Denmark has seen almost no change, but in Finland and Sweden, more adolescents say that they have tried cannabis and more also report heavy usage $[5,6]$. It cannot therefore be said that the development of cannabis use in Iceland is following a pattern known from the neighbouring countries.

Other individual and societal variables can affect the use of substance use among adolescents. Gender has been claimed as one of them, but as our results show, there is very little difference between Icelandic boys and girls in terms of use of alcohol and cannabis. A comparison of cross-sectional 30 HBSC countries data from 2002 to 2010 [8] showed that although male and female cannabis consumption patterns became more similar in some countries (e.g. Belgium, Canada, Czech Republic, Denmark, Estonia, Germany, Poland, Russia and Spain), in others, the gap widened (e.g. Austria, Finland, France, Hungary, Ireland, Italy, the Netherlands, Portugal, Ukraine and United Kingdom). An overall decline was found for both genders, but this decline was steeper for girls compared with boys. Simons-Morton et al. [15] looked at alcohol use prevalence and drunkenness in 20 countries in Europe and North America in the HBSC study from 1998 to 2006. They found that while trends in alcohol use and drunkenness varied by country, it remained higher among boys than girls, but that the gap was declining and in some countries, the girls appeared to be catching up with boys. Similar results have also been reported from the ESPAD study both with regard to alcohol and cannabis use. Some authors have linked this to emancipation of woman [8], and given that Iceland has repeatedly had the best outcome on the Gender Gap Index [16], it may well be that our results reflect just that.

Our results do not indicate that the radical reduction in adolescent drinking is due to a corresponding change in their attitudes towards the dangers of alcohol. More students claimed that drinking five or more drinks each weekend carried great risk in 1995 than in 2015, but more students also said that no risk would be involved. Despite efforts to educate Icelandic adolescents about the hazards of consumption, significantly more students in 2015 than in 1995 said they were not sure about whether such a drinking pattern was dangerous or not. The adolescent's attitude towards cannabis became more positive during the 20 year period. We find that on an individual level, perceived risk consistently reduces the risk of both alcohol and cannabis use, but changes in it from 1995 to 2015 do not explain the general trend in consumption almost all of the heavy users. More likely explanation for the reduced drinking is parental monitoring, which has increased greatly during this period and reduced availability. Increased parental monitoring decreased the risk of cannabis use both in 1995 
and 2015 and the risk of drinking in 2015. This again reflects a change in attitudes among Icelandic parents towards adolescent drinking.

It will be of crucial importance to Icelandic health authorities to tackle this rise in heavy cannabis use, but also worrying is that Icelandic adolescents seem to be less concerned with associated health risks. Over time more and more studies have demonstrated the risk that cannabis use of youths can pose to their developing brains, although causality is difficult to determine because of the possibility of common causal agents $[2,17,18]$. The results call for additional efforts in intervention specifically aimed at young heavy users of cannabis. Education regarding the risk of heavy cannabis use may be a key factor, but many youths and stakeholders (guidance counsellors, teachers, youth workers, etc.) may not be aware of the richness of the data we now have linking heavy cannabis use to the development of severe and persistent psychotic illnesses later in life. As previously shown in a study by de Looze et al. [1], our data reveal a clustering of substance abuse, but the pattern has changed from 1995 to 2015 in that 10 times more heavy users of alcohol have become heavy users of cannabis as well, but heavy users of cannabis have become half as likely to drink alcohol so frequently. It is obviously of pivotal importance to identify the variables explaining this clustering as adolescent use of both cannabis and alcohol leads to more serious problems than use of either substance alone [19].

The development of cannabis and alcohol use in Icelandic adolescents over the past 20 years is also interesting in the context of the normalisation thesis [20], which states that the frequency of substance use among adolescents is dependent on the distribution of these behaviours in the larger population. It would predict that: (i) when population level use increases, low risk adolescents will be more likely to use; and (ii) adolescents facing multiple risk factors will be equally likely to use, regardless of trends in population level use. In accordance with a recent study from Israel on drunkenness and smoking [21], our results contradict this theory. In terms of alcohol use, the percentage of both low-risk and high-risk use has decreased even though there has been a marked increase in the general population. Increase in cannabis use is only seen among high-risk adolescents while the percentage of those who have tried it has remained stable for two decades. The results, however, contradict the premise of problem behaviour theory [9] because of the reduction in drinking should be accompanied with a reduction in cannabis use.

Prevention policies aimed at Icelandic adolescents have focused on close co-operation between parents, schools, youth clubs, police and other guardians.
Declining alcohol use has been seen as proof of success for this integrated approach. The current study indicates that the drastic reduction in adolescent drinking does not seem to be due to changes in their attitudes, but rather due to much more parental monitoring and reduced availability of alcohol. The concurrent increase in heavy cannabis use among Icelandic adolescents could be considered as an example of the polarisation in the nation's youth culture suggested by Bjarnason in 2004 [4]. It seems unlikely that the same prevention measures will be successful in reaching the more vulnerable group.

Our study has strengths and limitations that are important to be aware of. The main strength is of course that the first five waves of study were based on a whole population rather than a sample. Unfortunately, that means that the drop in participation rate in the sixth wave counts as a limitation. Secondly, because this is a cross-sectional study, no causal relationships can be inferred. Thirdly, it is reasonable to maintain a healthy scepticism towards self-reported data. It is however worth mentioning that among adolescents, studies have shown that anonymous selfreports tend to give more valid data on sensitive issues compared with other methods [22].

\section{Acknowledgement}

The study is supported by grants from the Icelandic Directorate of Health, KEA and the University of Akureyri.

\section{Conflict of interest}

The authors have no conflicts of interest in reporting the current study. The study sponsors had no say in the study design, the collection, analysis and interpretation of data, the writing of the report or the decision to submit the manuscript for publication.

\section{References}

[1] de Looze M, ter Bogt TFM, Raaijmakers QAW, Pickett W, Kuntsche E, Vollebergh WAM. Cross-national evidence for the clustering and psychosocial correlates of adolescent risk behaviours in 27 countries. Eur J Public Health 2015;25:50-56.

[2] Lubman DI, Yucel M, Hall WD. Substance use and the adolescent brain: a toxic combination? J Psychopharmacol 2007;21:792-794.

[3] Murphy K, Sahm L, McCarthy S, Lambert S, Byrne S. Substance use in young persons in Ireland, a systemic review. Addict Behav 2013;38:2392-2401.

[4] Bjarnason T. Polarization in alcohol consumption among Icelandic adolescents, 1995-2003. Nordisk Alkohol Nark 2004;23:51-58.

[5] Hibell B, Anderson B, Bjarnason T, Kokkevi A, Morgan M, Narusk A. The 1995 ESPAD Report: Alcohol and Other Drug Use Among Students in 26 European Countries. Stockholm: The Swedish Council for Information on Alcohol and Other Drugs (CAN), 1997.

[6] Hibell B, Guttormsson U, Ahlström S, et al. The 2011 ESPAD Report: Substance Use among Students in 36 European Countries. Stockholm: 
The Swedish Council for Information on Alcohol and Other Drugs (CAN), 2012.

[7] Kristiansson AL, Sigfusdottir ID, Thorlindsson T, Mann MJ, Sigfusson J, Allegrante JP. Population trends in smoking, alcohol use and primary prevention variables among adolescents in Iceland, 1997-2014. Addiction 2016;111:645-652.

[8] ter Bogt TFM, de Looze M, Molcho M, et al. Do societal wealth, family affluence and gender account for trends in adolescent cannabis use? A 30 country cross-national study. Addiction 2014;109:273-283.

[9] Jessor R, Jessor SL. Problem Behavior and Psychosocial Development: A Longitudinal Study of Youth. New York: Academic Press, 1977.

[10] Stone AL, Becker LG, Huber AM, Catalano RF. Review of risk and protective factors of substance use and problem use in emerging adulthood. Addict Behav 2012;37:747-775.

[11] Van Petegem S, Vansteenkiste M, Beyers W. The jingle-jangle fallacy and adolescent autonomy in the family: in search of its underlying structure. J Youth Adolesc 2013;42:994-1014.

[12] The ESPAD Group. ESPAD Report 2015: results from the European School Survey Project on Alcohol and Other Drugs. Luxembourg: Publications Office of the European Union, 2016.

[13] Organisation for Economic Co-operation and Development. Non-Medical Determinants of Health. Available at: http://stats.oecd.org/Index. aspx?DataSetCode=HEALTH_LVNG\# (accessed March 2017).
[14] Gunnlaugsson H. Fíkniefnavandinn á Íslandi. Próun neyslu, neyslumynstur og kostir í stefnumótun. Bjóðarspegillinn 2013;XIV:1-11.

[15] Simons-Morton BG, Farhat T, ter Bogt TF, et al. Gender specific trends in alcohol use: cross-cultural comparisons from 1998 to 2006 in 24 countries and regions. Int J Pub Health 2009;54:199-208.

[16] World Economic Forum (2016). The Global Gender Gap Report 2015. Geneva: World Economic Forum.

[17] Rubino T, Parolaro D. The impact of exposure to cannabinoids in adolescence: insights from animal models. Biol Psychiatry 2016;79:578-585.

[18] Volkow ND, Swanson JM, Evins AE, et al. Effects of cannabis use on human behavior, including cognition, motivation, and psychosis: a review. JAMA Psychiat 2016;73:292-297.

[19] Stenbacka M. Problematic alcohol and cannabis use in adolescence-risk of serious adult substance abuse? Drug Alcohol Rev 2003;22:277-286.

[20] Measham F, Newcombe R, Parker H. The normalization of recreational drug use amongst people in north-west England. $\mathrm{Br} \mathrm{J}$ Sociol 1994;45:287-312.

[21] Sznitman SR, Zlotnick C, Harel-Fisch Y. Normalisation theory: does it accurately describe temporal changes in adolescent drunkenness and smoking? Drug Alcohol Rev 2016;35:424-432.

[22] Safer DJ. Self-reported suicide attempts by adolescents. Ann Clin Psychiatry 1997;9:263-269. 